\title{
Prognostic factors of severity of invasive community- acquired Staphylococcus aureus infections in children
}

\author{
Soraya Araya, M.D. ${ }^{a}$, Fernando Galeano, M.D. ${ }^{a}$, Sara Amarilla, M.D. ${ }^{a}$, \\ Nicolás González, M.D. ${ }^{a}$, Silvio Apodaca, M.D. ${ }^{a}$, Dolores Lovera, M.D. ${ }^{a}$, and \\ Antonio Arbo, M.D., MSc $c^{a, b}$
}

\begin{abstract}
Objective: To describe the clinical characteristics of invasive Staphylococcus aureus infections in children and identify the prognostic factors of severity and mortality.

Materials and methods: Observational study in patients $<16$ years old hospitalized between 2010 and 2015 due to invasive S. aureus infections at the Instituto de Medicina Tropical, in Asunción, Paraguay. Patients were distributed based on whether or not they required admission to the intensive care unit, and clinical, laboratory, and evolutionary outcome measures were compared.
\end{abstract}

Results: Out of the 107 included patients, $50(47 \%)$ developed bacteremia; $50(47 \%)$, pneumonia; and $21(19 \%)$, multifocal disease. Among the patients who were admitted to the intensive care unit $(41 \%)$, prior antibiotic use $(p<0.05)$, the presence of bacteremia $(p=0.01)$, the presence of comorbidities $(p<0.05)$, and multifocal disease $(p<0.01)$ were more frequent. The overall mortality rate was $15 \%$. The mortality-associated risk factors were the presence, at the time of admission, of hypotension $(p<0.01)$, multifocal disease $(p<0.01)$, bacteremia $(p<0.01)$, leukopenia $(p<0.01)$, severe anemia $(p<0.01)$, and metabolic acidosis $(p<0.01)$, among others.

Conclusions: The prognostic factors of severity included prior antibiotic use, bacteremia, the presence of comorbidities, and presentation with multifocal disease. Mortality was significant; associated risk factors included the presence, at the time of admission, of hypotension, multifocal disease, leukopenia, severe anemia, and metabolic acidosis.

Key words: Staphylococcus aureus, invasive staphylococcal infections, children, risk factors.

a. Instituto de Medicina Tropical.

b. Universidad Nacional de Asunción, Paraguay.

E-mail address:

Antonio Arbo, M.D.: antonioarbo@hotmail. com

Funding:

None.

Conflict of interest:

None.

Received: 11-29-2018

Accepted: 6-2-2019

http: / / dx.doi.org/10.5546/ aap.2019.eng.381

\section{INTRODUCTION}

In the past two decades, community-acquired methicillinresistant Staphylococcus aureus (MRSA) infections have emerged worldwide..$^{1-3}$ In Latin America, the first cases of community-acquired (CA) MRSA infections were reported in Uruguay in 2001; ${ }^{4}$ after this, several countries, ${ }^{5-8}$ including Paraguay, ${ }^{9}$ have reported that the prevalence of methicillin resistance ranges from $25 \%$ to $70 \% .^{10}$

Taking into account the severity associated with community-acquired $S$. aureus infections, ${ }^{11}$ in this new setting of antimicrobial susceptibility, it is especially relevant to identify the factors inherent to the host and bacteria, which may be considered prognostic factors of severity at the time of patient hospitalization. Although several studies have assessed these factors in the adult population, the information in this regard in the pediatric population is limited. Therefore, the objective of this study was to describe the clinical characteristics of invasive Staphylococcus aureus infections in children and identify the prognostic factors of severity and mortality.

\section{MATERIALS AND METHODS Study population and design}

This was a descriptive, retrospective, and cross-sectional study carried out at the Instituto
To cite: Araya S, Galeano F, Amarilla S, González N, et al. Prognostic factors of severity of invasive community-acquired Staphylococcus aureus infections in children. Arch Argent Pediatr 2019;117(6):381-387. de Medicina Tropical, in Asunción, Paraguay, the leading national referral facility for infectious diseases. Patients younger than 16 years, diagnosed upon discharge with invasive S. aureus infection and hospitalized between 2010 and 2015 were included.

Invasive $S$. aureus infection was defined as the presence of an 
infection with concomitant isolation of $S$. aureus in usually sterile sites, including blood, pleural fluid, cerebrospinal fluid, joint fluid, bone, pericardial fluid, peritoneal fluid or other internal body site. Cases of infections limited to the skin and soft tissue were excluded, unless they were associated with a systemic inflammatory response syndrome. Patients who were transferred from other facilities, who had an incomplete medical record in terms of study outcome measures, and who had S. aureus isolation in samples collected after 48 hours of hospitalization were excluded.

Data were collected in a standardized sheet. The following outcome measures were included: clinical, demographic (sex, age, comorbidity), type of infection (multiple sources, pneumonia, osteomyelitis, myocarditis, meningitis, endocarditis), laboratory (white blood cells [WBC], hemoglobin, platelets, hypoalbuminemia, bacteremia, etc.), microbiological (susceptibility pattern), and evolutionary (need for admission to the intensive care unit [ICU], assisted mechanical ventilation [AMV], presence of kidney or liver failure). The microbiological characteristics of $S$. aureus and antimicrobial sensitivity were established using the Vitek ${ }^{\circledR}$ automated identification system (BioMérieux).

Patients with hypotension, respiratory insufficiency (oxygen saturation $\left[\mathrm{SaO}_{2}\right]<90 \%$ on room air or a fraction of inspired oxygen $\left[\mathrm{FiO}_{2}\right]>50 \%$ required to maintain $\mathrm{SaO}_{2}$ at $92 \%$ or higher), poor respiratory dynamics (accessory muscle use, nasal flaring, respiratory rate $>2$ standard deviations [SDs] for age) or a consciousness disorder required admission to the ICU.

\section{Statistical analysis}

After the general analysis, patients were stratified based on whether or not they had been admitted to the ICU and on their status upon discharge (dead or alive). The different demographic, clinical, and laboratory outcome measures, and their association with the severity of invasive $S$. aureus infections were analyzed in relation to ICU admission and mortality. Comparative analyses were done using Student's $t$ test for parametric outcome measures and the $\chi^{2}$ test to compare proportions. To analyze risk factors, the odds ratio (OR) and the corresponding $95 \%$ confidence interval $(\mathrm{CI})$ were estimated.

\section{Ethics}

The study was approved by the Institutional Ethics Committee. Given the study's retrospective, secondary source nature, no informed consent was requested, and investigators ensured the anonymity of participating patients.

\section{RESULTS}

\section{General characteristics}

During the study period, 418 patients were hospitalized with $S$. aureus isolation in a sterile site in the first 48 hours of admission. Of them, $107(26 \%)$ had invasive infections. The patients' mean age was $75 \pm 56$ months, with a slight prevalence of male sex (58\% versus $42 \%$ ). More infections were observed in children older than 5 years $(n=50)$ compared to those younger than 2 years $(\mathrm{n}=20)$ and to the $2-5$ year-old group $(\mathrm{n}=37)(p<0.05)$.

Invasive infections corresponded to pneumonia $(n=50)$, osteomyelitis $(n=30)$, multifocal disease ( $\mathrm{n}=21$; in 2 cases, with endocarditis), meningitis $(\mathrm{n}=4)$, and primary endocarditis $(n=2)$. Bacteremia was confirmed in $50 / 107$ patients $(47 \%)$, which corresponded to $20 \%$ of those with pneumonia $(n=10), 30 \%$ of those with osteomyelitis $(\mathrm{n}=9), 100 \%$ of those with multifocal disease $(n=21)$, the 2 cases of primary endocarditis, and the 4 cases of meningitis.

Comorbidities were observed in 34 patients $(32 \%)$; atopy $(\mathrm{n}=11,10 \%)$ and nutritional disorders (malnutrition [ $\mathrm{n}=7]$ and obesity $[n=4]$ ) were the most common ones. Other causes of comorbidity included asthma $(n=4)$, corticosteroid use $(n=4)$, and human immunodeficiency virus (HIV) infection $(\mathrm{n}=4)$. In addition, $44 \%$ of patients had received antibiotics prior to hospitalization. Most patients had leukocytosis at the time of admission $(\mathrm{X} \pm \mathrm{SD}$ : $\left.16200 \pm 5505 / \mathrm{mm}^{3}\right)$, and moderate to severe anemia was observed in 40 cases $(37 \%)$. The overall mortality rate was $15 \%$ (Table 1 ).

\section{Characteristics of patients with methicillin- resistant and methicillin-sensitive Staphylococcus aureus infections}

Out of 107 S. aureus isolations, $42(39 \%)$ were resistant to oxacillin (MRSA). Methicillin-sensitive S. aureus (MSSA) infections predominated among patients younger than 5 years $(69 \%)$, whereas MRSA infections were more common among those older than 5 years $(70 \%)(p<0.001)$. Whereas $83 \%$ of MRSA infections were observed 
in male patients, only $42 \%$ of MSSA infections corresponded to male patients $(p<0.001)$ (Table 2$)$. The frequency of comorbidities $(p=0.02)$, as well as pneumonia $(p=0.04)$, bacteremia $(p=0.01)$, and multifocal disease $(p=0.02)$, was higher among patients with MRSA infections (Table 2). Although no differences were observed in mortality between MRSA and MSSA infections, admission to the ICU was significantly higher among the patients with MRSA infections (60\% versus $29 \%, p=0.01$ ) (Table 2 ).

\section{Admission to the intensive care unit}

A total of 44 patients $(41 \%)$ were admitted to the ICU (Table 3). When comparing those who were admitted to the ICU and those who did not require such admission $(n=63)$, no difference was observed in the mean age of patients in both groups $(72 \pm 61$ months old versus $75.4 \pm 57$ months, $p>0.5$ ); however, male sex predominated among those who required it $(54.5 \%$ versus $31.7 \%)(p<0.05)$. Antibiotic use prior to hospitalization $(p<0.001)$ and the

Table 1. Clinical and demographic characteristics of patients with invasive community-acquired Staphylococcus aureus infections

\begin{tabular}{lcc}
\hline Outcome measure & Number & Percentage $(\%)$ \\
\hline Patients & 107 & 100 \\
Mean age (years) (mean \pm SD) & $6.25 \pm 4.7$ & 18.7 \\
$<2$ years old & 20 & 34.6 \\
$2-5$ years old & 37 & 46.7 \\
$>5$ years old & 50 & $58 / 42$ \\
Male/ female & $62 / 45$ & 47 \\
Bacteremia & 50 & 47 \\
Pneumonia & $50 *$ & 19.6 \\
Multifocal disease & 21 & 28 \\
Osteomyelitis & 30 & 3.7 \\
Endocarditis & 4 & 7.5 \\
Myocarditis & 8 & 3.7 \\
Meningitis & 4 & 41 \\
Admission to the ICU & 44 & 25 \\
AMV & 27 & 15 \\
Deaths & 16 & \\
\hline
\end{tabular}

* Empyema: 11 patients.

SD: standard deviation; ICU: intensive care unit; AMV: assisted mechanical ventilation.

TABLE 2. Characteristics of patients with methicillin-resistant and methicillin-sensitive Staphylococcus aureus infections

\begin{tabular}{|c|c|c|c|}
\hline Outcome measure (number) & $\begin{array}{c}\text { MRSA infections } \\
\begin{array}{c}\mathrm{N}=42 \\
\mathrm{n}(\%)\end{array}\end{array}$ & $\begin{array}{c}\text { MSSA infections } \\
\begin{array}{c}\mathrm{N}=65 \\
\mathrm{n}(\%)\end{array}\end{array}$ & $p$ value \\
\hline \multicolumn{4}{|l|}{ Age group } \\
\hline$\leq 5$ years old & $12(29)$ & $45(69)$ & $<0.0001$ \\
\hline$>5$ years old & $30(71)$ & $20(31)$ & $<0.0001$ \\
\hline Male sex & $35(83)$ & $27(42)$ & $<0.0001$ \\
\hline Female sex & $7(17)$ & $38(58)$ & $<0.0001$ \\
\hline Comorbidity & $21(50)$ & $13(20)$ & 0.02 \\
\hline Pneumonia $(n=50)^{*}$ & $25(60)$ & $25(38)$ & 0.04 \\
\hline Osteomyelitis $(\mathrm{n}=30)^{*}$ & $16(38)$ & $14(22)$ & 0.07 \\
\hline Bacteremia $(n=50)^{*}$ & $26(62)$ & $24(37)$ & 0.01 \\
\hline Endocarditis $(n=4)^{*}$ & $3(7)$ & $1(1.5)$ & 0.29 \\
\hline Multifocal disease $(n=21)^{*}$ & $13(31)$ & $8(12)$ & 0.02 \\
\hline Admission to the ICU $(\mathrm{n}=44)$ & $25(60)$ & $19(29)$ & 0.002 \\
\hline Deaths $(n=16)$ & $6(14)$ & $10(15)$ & 0.5 \\
\hline
\end{tabular}

* Some patients had more than one condition.

ICU: intensive care unit; MRSA: methicillin-resistant Staphylococcus aureus infection;

MSSA: methicillin-sensitive Staphylococcus aureus infection. 
presence of comorbidities $(p<0.01)$ were more common among the patients admitted to the ICU. When comparing the types of invasive S. aureus infection, the presence of pneumonia (30/44 versus $20 / 63, p<0.001)$ and multifocal disease $(18 / 44$ versus $3 / 63, p<0.001)$ predominated among patients admitted to the ICU (Table 3 ). Likewise, the presence of bacteremia $(p=0.01)$ was clearly higher among those admitted to the ICU (Table 3). When comparing the length of stay, it was longer among the patients admitted to the ICU versus those that did not require it (20 \pm 19 days versus $13 \pm 15$ days, $p<0.05$ ). Lastly, mortality was significantly higher among the patients admitted to the ICU $(p<0.001)$ (Table 3).
The analysis of lab test characteristics showed that the presence of a WBC count $<5000 / \mathrm{mm}^{3}$ $(p=0.02)$, severe anemia $<7 \mathrm{~g} / \mathrm{dL}(p=0.03)$, and thrombocytopenia $<100000 / \mathrm{mm}^{3}(p=0.02)$ were more common among the patients admitted to the ICU (Table 4). Also, a higher number of patients admitted to the ICU showed elevated transaminases $>3$ times the normal value $(p<0.01)$, metabolic acidosis $(p<0.01)$, and hypoalbuminemia $<3.5 \mathrm{~g} / \mathrm{dL}(p<0.001)$ (Table 4$)$. The frequency of methicillin resistance was significantly higher among the patients who required admission to the ICU $(p<0.01)$ (Table 4$)$.

The outcome measures associated with mortality were the presence, at the time of

TABLE 3. Prognostic factors of severity in patients with invasive community-acquired Staphylococcus aureus infections

\begin{tabular}{|c|c|c|c|c|}
\hline Clinical outcome measures & $\begin{array}{l}\text { Admission } \\
\text { to the ICU } \\
\begin{array}{c}\mathrm{N}=44 \\
\mathrm{n}(\%)\end{array}\end{array}$ & $\begin{array}{l}\text { Admission } \\
\text { to the general ward } \\
\mathrm{N}=63 \\
\mathrm{n}(\%)\end{array}$ & $p$ value & $\begin{array}{l}\text { Odds ratio } \\
\text { (95\% CI) }\end{array}$ \\
\hline Mean age (months) (mean \pm SD) & $72 \pm 61$ & $75.4 \pm 57$ & $>0.5$ & \\
\hline Male sex & $24(54.5)$ & $20(31.7)$ & $<0.05$ & $2.58(1.16-5.71)$ \\
\hline Prior antibiotic use & $33(74)$ & $14(22)$ & $<0.001$ & $10.50(4.24-25.94)$ \\
\hline Comorbidity & $22(50)$ & $12(19)$ & $<0.01$ & $4.25(1.79-10.07)$ \\
\hline Multifocal disease & $18(41)$ & $3(4.7)$ & $<0.001$ & $13.84(3.75-51.11)$ \\
\hline Pneumonia & $30(68)$ & $20(31.7)$ & $<0.001$ & $4.60(2.01-10.53)$ \\
\hline Osteomyelitis & $10(23)$ & $20(31.7)$ & 0.30 & $0.63(0.26-1.52)$ \\
\hline Endocarditis & $2(4.5)$ & $2(3)$ & 0.71 & $1.45(0.19-10.72)$ \\
\hline Meningitis & $4(9)$ & $0(0)$ & $<0.1$ & $14.11(0.73-269.13)$ \\
\hline Hypotension & $26(59)$ & $1(1.6)$ & $<0.001$ & 89.55 (11.35-706.25) \\
\hline Bacteremia & $27(61)$ & $23(36.5)$ & 0.01 & $2.76(1.24-6.11)$ \\
\hline Deaths & $14(32)$ & $2(3.1)$ & $<0.001$ & $14.23(3.03-66.70)$ \\
\hline
\end{tabular}

ICU: intensive care unit; SD: standard deviation; CI: confidence interval.

TABLE 4. Laboratory prognostic factors of severity in patients with invasive community-acquired Staphylococcus aureus infections

\begin{tabular}{|c|c|c|c|c|}
\hline Laboratory outcome measures & $\begin{array}{l}\text { Admitted } \\
\text { to the ICU } \\
\begin{array}{c}\mathrm{N}=44 \\
\mathrm{n}(\%)\end{array}\end{array}$ & $\begin{array}{l}\text { Admitted } \\
\text { to the general ward } \\
\begin{array}{c}\mathrm{N}=63 \\
\mathrm{n}(\%)\end{array}\end{array}$ & p value & $\begin{array}{l}\text { Odds ratio } \\
\text { (95\% CI) }\end{array}$ \\
\hline WBC count $/ \mathrm{mm}^{3}(X \pm \mathrm{SD})$ & $16185 \pm 9210$ & $16232 \pm 5505$ & 0.5 & \\
\hline $\mathrm{WBC}>15000 / \mathrm{mm}^{3}$ & $27(61.4)$ & $29(46)$ & 0.10 & $1.86(0.85-4.07)$ \\
\hline $\mathrm{WBC}<5000 / \mathrm{mm}^{3}$ & $7(15.9)$ & $0(0)$ & 0.02 & $25.40(1.41-457.52)$ \\
\hline Mean $\mathrm{Hb}(\mathrm{g} / \mathrm{dL})$ & $9.6+2.6$ & $11+1.9$ & $>0.1$ & \\
\hline $\mathrm{Hb}<7 \mathrm{~g} / \mathrm{dL}$ & $6(13.6)$ & $0(0)$ & 0.03 & $21.44(1.17-391.33)$ \\
\hline Platelet count $/ \mathrm{mm}^{3}(\mathrm{X} \pm \mathrm{SD})$ & $267667 \pm 180494$ & $318376 \pm 218296$ & $>0.1$ & \\
\hline Platelets < $100000 / \mathrm{mm}^{3}$ & $7(15.9)$ & $0(0)$ & 0.02 & $25.40(1.41-457.52)$ \\
\hline GOT or GPT > 3 times the normal value & $14(31.8)$ & $5(7.9)$ & $<0.01$ & $5.41(1.78-16.46)$ \\
\hline Prothrombin time $<60 \%$ & $10(22.7)$ & $2(3.2)$ & $<0.01$ & $8-97(1.85-43.33)$ \\
\hline Bicarbonate $<15 \mathrm{mEq} / \mathrm{L}$ & $11(25)$ & $1(1.6)$ & $<0.01$ & $20.66(2.55-167.13)$ \\
\hline $\mathrm{pH} \leq 7.2$ & $14(31.8)$ & $0(0)$ & $<0.01$ & $60.37(3.48-1046.00)$ \\
\hline Low albumin $(<3.5 \mathrm{~g} / \mathrm{dL})$ & $18(40.9)$ & $2(3.1)$ & $<0.001$ & $21.11(4.56-97.64)$ \\
\hline \multicolumn{5}{|l|}{ Antibiotic sensitivity } \\
\hline Methicillin resistance & $25(57 \%)$ & $17(27)$ & $<0.01$ & $3.56(1.57-8.04)$ \\
\hline TMP-SMX resistance & $5(11.4)$ & $2(3.2)$ & $>0.1$ & $3.91(0.72-21.15)$ \\
\hline Clindamycin resistance & $3(6.8)$ & $1(1.6)$ & $>0.1$ & $4.53(0.45-45.12)$ \\
\hline
\end{tabular}

WBC: white blood cells; $\mathrm{Hb}$ : hemoglobin; ICU: intensive care unit; CI: confidence interval; SD: standard deviation; TMP-SMX: thrimethoprim-sulfamethoxazole; GOT: glutamic-oxaloacetic transaminase; GPT: glutamic-pyruvic transaminase. 
admission, of hypotension (OR: 15.20; $95 \%$ CI: 4.31-53.57; $p<0.001$ ), bacteremia (OR: 6.32; $95 \%$ CI: $1.68-23.75 ; p<0.01$ ), pneumonia (OR: 12.16; $95 \%$ CI: 3.50-42.19; $p<0.01)$, and a diagnosis of multifocal disease (OR: 42.50; 95 \% CI: 10.45-172.71; $p<0.01$ ) (Table 5). In relation to lab test information at the time of admission, the presence of a WBC count $<5000 / \mathrm{mm}^{3}$ (OR: 20.22; $95 \%$ CI: 3.49-117.03; $p<0.001$ ), severe anemia (hemoglobin $<7 \mathrm{~g} / \mathrm{dL}$ ) (OR: 40.90; $95 \%$ CI: 4.37-382.92; $p<0.01$ ), metabolic acidosis (OR: 40.90; 95 \% CI: 4.37-382.92; $p<0.01$ ), and $S$. aureus isolation with clindamycin resistance (OR: 20.76; $95 \%$ CI: 2.00-214.90; $p=0.01$ ) were identified as risk factors associated with mortality. The presence of methicillin resistance was not associated with a higher mortality (Table 5).

\section{DISCUSSION}

In this study, all patients with invasive S. aureus infections hospitalized in a referral facility for infectious diseases in Paraguay in a 5-year period were analyzed. Invasive $S$. aureus infections were observed mostly in schoolchildren (50\% of cases), and this is similar to what has been reported in other $S$. aureus bacteremia series conducted in our region, such as in Argentina or Uruguay. ${ }^{5-7}$ The fact that the skin is usually the source of $S$. aureus infections and that schoolchildren are more prone to suffer wounds or minor traumas on the skin may partially explain such observation. However, in other series, especially those carried out in the United States of America (USA) ${ }^{12,13}$ or Asia, ${ }^{14}$ community-acquired $S$. aureus infections were mainly observed in children younger than 3 years.

Although $32 \%$ of patients had a comorbidity which was, in general, of unmarked severity, like atopy or malnutrition, most patients with invasive S. aureus infections were immunocompetent. This is different from other series done both in the USA and Europe. ${ }^{12,15,16}$
Forty percent of $S$. aureus causing invasive infections in this series was methicillin-resistant. These findings demonstrate that the growing epidemics of methicillin-resistant $S$. aureus, which has been reported in different countries in both the Northern and Southern hemispheres, has not escaped our country, thus anticipating the increase in resistance to be seen in the next years.

Our series shows the severity of invasive S. aureus infections. Admission to the ICU was required in $41 \%$ of cases. Although no differences were observed in the mean age between the patients who required admission to the ICU and those who did not, more male patients required it. It is known that sex has a major impact on the outcomes of a series of infectious diseases. ${ }^{17}$ The presence of comorbidities was a factor associated with admission to the ICU, which is not surprising because the integrity of the immune system is critical in the response of the host to the infection. ${ }^{18}$ In addition, the frequency of prior antibiotic use was higher among the patients who were admitted to the ICU. This may have affected the delay in the visit to the doctor's office for those who were receiving treatment and may have had an impact on the severity of the condition. This has already been observed in cases of community-acquired pneumonia. ${ }^{19}$

The presence of bacteremia $(p=0.01)$, pneumonia $(p<0.01)$, and clinical presentation with multifocal disease $(p<0.01)$ correlated to the admission to the ICU. These findings are not surprising because the presence of a microorganism in the blood is usually accompanied by cytokine activation, which leads to a systemic inflammatory response syndrome. ${ }^{20}$ The severity of $S$. aureus pneumonia has been widely documented and, in our series, this has been confirmed because $68 \%$ of patients admitted to the ICU had pneumonia. In the study by M. A. Carrillo-Márquez et al., ${ }^{21} 58 \%$

TABLE 5. Mortality-associated prognostic factors in patients with invasive Staphylococcus aureus infections

\begin{tabular}{|c|c|c|c|c|c|}
\hline Outcome measure & Total & $\begin{array}{c}\text { Deaths } \\
\mathrm{N}=16 \\
\mathrm{n}(\%)\end{array}$ & $\begin{array}{l}\text { Survivors } \\
\begin{array}{c}\mathbf{N}=91 \\
\mathbf{n}(\%)\end{array}\end{array}$ & $p$ value & $\begin{array}{l}\text { Odds ratio } \\
\text { (95\% CI) }\end{array}$ \\
\hline Hypotension & 27 & $12(75.0)$ & $15(16.5)$ & $<0.001$ & $15.20(4.31-53.57)$ \\
\hline Bacteremia & 50 & $13(81.2)$ & $37(40.6)$ & $<0.01$ & $6.32(1.68-23.75)$ \\
\hline Pneumonia & 30 & $12(75.0)$ & $18(19.8)$ & $<0.01$ & $12.16(3.50-42.19)$ \\
\hline Multifocal disease & 18 & $12(75.0)$ & $6(6.6)$ & $<0.001$ & $42.50(10.45-172.71)$ \\
\hline Leukopenia & 7 & $5(31.2)$ & $2(2.2)$ & $<0.001$ & $20.22(3.49-117.03)$ \\
\hline Severe anemia $(\mathrm{Hb}<7)$ & 6 & $5(31.2)$ & $1(1.1)$ & $<0.01$ & $40.90(4.37-382.92)$ \\
\hline Metabolic acidosis $($ bic $<15)$ & 14 & $8(50.0)$ & $6(6.6)$ & $<0.001$ & $14.16(3.92-51.10)$ \\
\hline Methicillin resistance & 42 & $6(37.5)$ & $36(39.5)$ & 0.87 & $0.91(0.30-2.74)$ \\
\hline Clindamycin resistance & 4 & $3(18.7)$ & $1(1.1)$ & 0.01 & $20.76(2.00-214.90)$ \\
\hline
\end{tabular}

$\mathrm{Hb}$ : hemoglobin; CI: confidence interval. 
of pneumonia cases required admission to the ICU. The incidence of metastatic sources in S. aureus bacteremias ranges from $15 \%$ to $68 \%$ in different studies and accounts for a marker of severity. ${ }^{16,22,23}$

Among the patients admitted to the ICU, MRSA was isolated in $57 \%$, which was a significantly higher proportion than among those who did not require admission to the ICU $(p<0.01)$. MRSA infections were more severe (higher frequency of pneumonia, bacteremia, and multifocal disease) (Table 2), which may explain the higher frequency of admission to the ICU.

Our study has allowed us to identify laboratory outcome measures associated with a greater severity in the setting of staphylococcal infections. In this regard, the presence, at the time of admission, of leukopenia $\left(<5000 / \mathrm{mm}^{3}\right)$ $(p=0.02)$, severe anemia $<7 \mathrm{~g} / \mathrm{dL}(p=0.03)$, and thrombocytopenia $<100000 / \mathrm{mm}^{3}(p=0.02)$ were significantly more common in the patients admitted to the ICU. Such associations had already been reported by other authors. ${ }^{24-27}$

The mortality rate due to invasive $S$. aureus infections in our study was significant (15\%). Although it was similar to that observed in other studies ${ }^{28}$ mortality may be higher than $48 \% .{ }^{11}$ However, other studies have reported a much lower mortality rate. Thus, in the study conducted in Argentina by G. Pérez et al., ${ }^{7}$ the mortality rate was $6 \%$; in the study done in Europe by M. Gijón et al., ${ }^{15} 2 \%$; in the study by D. Engelman et al. ${ }^{22}$ or in the one by McMullan et al., ${ }^{29}$ in Australia, between $2 \%$ and $4 \%$; and in the study by J. S. Gerber et al., ${ }^{12}$ in the USA, $1 \%$. The high mortality rate observed in our series may be partially explained by the severity of cases hospitalized in this referral facility.

In this study, several mortality-associated risk factors were identified, both clinical (presence, at the time of admission, of hypotension, pneumonia, multifocal disease) and laboratory (bacteremia, leukopenia, severe anemia, and metabolic acidosis). Some of these have already been reported in other studies. ${ }^{15,23,30}$

Our study poses several limitations. Since the inclusion criterion was $S$. aureus isolation, there is a potential bias that cultures were collected in patients who appeared to have a more severe condition at the emergency department. Besides, since the Instituto de Medicina Tropical is a referral hospital for infectious diseases, our population possibly accounts for the most severe cases observed in the community. Therefore, our results may not be fully extrapolated to the population of a general hospital.

Future multicenter studies are required to more clearly elucidate risk factors and define the most effective treatment regimens aimed at reducing the morbidity and mortality in invasive S. aureus infections.

\section{CONCLUSION}

Our results demonstrate the severity of invasive community-acquired S. aureus infections. This study has allowed us to identify the relevant clinical and laboratory risk factors for both infection severity and mortality.

\section{REFERENCES}

1. DeLeo FR, Otto M, Kreiswirth BN, Chambers HF. Community-associated meticillin-resistant Staphylococcus aureus. Lancet. 2010; 375(9725):1557-68.

2. Kaplan S. Community-acquired methicillin resistant Staphylococcus aureu sinfections in children. Semin Pediatr Infect Dis. 2006; 17(3):113-9.

3. Deurenberg RH, Vink C, Kalenic S, Friedrich AW, et al. The molecular evolution of methicillin-resistant Staphylococcus aureus. Clin Microbiol Infect. 2007; 13(3):222-35.

4. Galiana Villar A. Infección por Staphylococcus aureus meticilino-resistente adquirido en la comunidad. Arch Pediatr Urug. 2003; 74(1):26-9.

5. Pardo L, Vola M, Macedo-Viñas M, Machado V, et al. Community-associated methicillin-resistant Staphylococcus aureusin children treated in Uruguay. I Infect Dev Ctries. 2013; 7(1):10-6.

6. Paganini H, DelaLatta MP, Muller Opet B, Ezcurra G, et al. Estudiomulticéntrico sobre las infecciones pediátricas por Staphylococcus aureus meticilino-resistente provenientes de la comunidad en la Argentina. Arch Argent Pediatr. 2008; 106(5):397-403.

7. Pérez G, MartirenS, Reijtman V, Romero R, et al. Bacteriemia por Staphylococcus aureus adquirido en la comunidad en niños: estudio de cohorte 2010-2014. Arch Argent Pediatr. 2016; 114(6):508-13.

8. Acuña M, Benadof D, Jadue C, Homarzábal JC, et al. Staphylococcus aureus resistente a meticilina asociado a la comunidad (SARM-AC): comunicación de los primeros cuatro casos pediátricos descritos en Hospital de Niños Roberto del Río. Rev Chil Infectol. 2015; 32(3):350-6.

9. Irala Ledezma J, Sanabria G. Progresión de la resistencia a la oxacilina de Staphylococcus aureus aislados entre 20112013 en un hospital de referencia de Asunción-Paraguay. Rev Inst Med Trop (Paraguay). 2017; 12(1):5-9.

10. Jones RN, Guzman-Blanco M, Gales AC, Gallegos B, et al. Susceptibility rates in Latin American nations: report from a regional resistance surveillance program (2011). Braz J Infect Dis. 2013; 17(6):672-81.

11. Tong SY, Davis JS, Eichenberger E, Holland TL, et al. Staphylococcus aureus infections: epidemiology, pathophysiology, clinical manifestations, and management. Clin Microbiol Rev. 2015; 28(3):603-61.

12. Gerber JS, Coffin SE, Smathers SA, Zaoutis TE. Trends in the incidence of methicillin-resistant Staphylococcus aureus infection in children's hospitals in the United States. Clin Infect Dis. 2009; 49(1):65-71.

13. Kumarachandran G, JohnsonJK, Shirley D-A, GraffunderE, et al. Predictors of adverse outcomes in children with 
Staphylococcus aureus bacteremia. J Pediatr Pharmacol Ther. 2017; 22(3):218-26.

14. Qiao $Y$, Ning X, Chen Q, Zhao R, et al. Clinical and molecular characteristics of invasive community-acquired Staphylococcus aureus infections in Chinese children. BMC Infect Dis. 2014; 14:582.

15. Gijón M, Bellusci M, Petraitiene B, Noguera-Julian A, et al. Factors Associated with Severity in invasive communityacquired Staphylococcus aureus infections in children: a prospective European multi-center study. Clin Microbiol Infect. 2016; 22(7):643.e1-6.

16. Le J, Dam Q, Tran T, Nguyen A, et al. Epidemiology and hospital readmission associated with complications of Staphylococcus aureus bacteremia in pediatrics over a 25year period. Epidemiol Infect. 2017; 145(12):2631-9.

17. Muenchhoff M, Goulde PJR. Sex differences in pediatric infectious diseases. J Infect Dis. 2014; 209(Suppl 3):S120-6.

18. Boyd JH, Russell JA, Fjell CD. The meta-genome of sepsis: host genetics, pathogens and the acute immune response. J Innate Immun. 2014; 6(3):272-83.

19. Emery DP, Milne T, Gilchrist CA, Gibbons MJ, et al. The impact of primary care on emergency department presentation and hospital admission with pneumonia: a case-control study. NPJ Prim Care Respir Med.2015;25:14113.

20. Bosmann M, Ward PA. The inflammatory response in sepsis. Trends Immunol. 2013; 34)3):129-36.

21. Carrillo-Marquez MA, Hulten KG, Hammerman W, Lamberth L, et al. Staphylococcus aureus pneumonia in children in the era of community-acquired methicillinresistance at Texas Children's Hospital. Pediatr Infect Dis J. 2011; 30(7):545-50.

22. Engelman D, Hofer A, Davis JS, Carapetis JR, et al. Invasive Staphylococcus aureus Infections in Children in Tropical Northern Australia. J Pediat Infect Dis Soc. 2014; 3(4):304-11.
23. Miles F, Voss L, Segedin E, Anderson BJ. Review of Staphylococcus aureus infections requiring admission to a paediatric intensive care unit. Arch Dis Child. 2005; 90(12):1274-8.

24. Gillet $Y$, Vanhems P, Lina G, Bes M, et al. Factors predicting mortality in necrotizing community-acquired pneumonia caused by Staphylococcus aureus containing PantonValentine leukocidin. Clin Infect Dis. 2007; 45(3):315-21.

25. Khanafer N, Sicot N, Vanhems P, Dumitrescu O, et al. Severe leukopenia in Staphylococcus aureus necrotizing, community-acquired pneumonia: risk factors and impact on survival. BMC Infect Dis. 2013; 13:359.

26. Muady GF, Bitterman H, Laor A, Vardi M, etal. Hemoglobin levels and blood transfusion in patients with sepsis in Internal Medicine Departments. BMC Infect Dis. 2016; 16(1):569.

27. Wang JL, Chen SY, Wang JT, Wu GH, et al. Comparison of both clinical features and mortality risk associated with bacteremia due to community-acquired methicillinresistant Staphylococcus aureus and methicillin-susceptible S. aureus. Clin Infect Dis. 2008; 46(6):799-806.

28. GonzalezBE,Martinez-AguilarG,HultenKG,Hammerman WA, et al. Severe staphylococcal sepsis in adolescents in the era of community-acquired methicillin-resistant Staphylococcus aureus. Pediatrics. 2005; 115(3):642-8.

29. McMullan BJ, Bowen A, Blyth CC, Van Hal S, et al. Epidemiology and mortality of Staphylococcus aureus bacteremia in Australian and New Zealand children. JAMA Pediatr. 2016; 170(10):979-86.

30. Bassetti M, Trecarichi EM, Mesini A, Spanu T, et al. Risk factors and mortality of healthcare-associated and community-acquired Staphylococcus aureus bacteraemia. Clin Microbiol Infect. 2012; 8(9):862-9. 